\title{
Erratum to: a randomised translational trial of lifestyle intervention using a 3-tier shared care approach on pregnancy outcomes in Chinese women with gestational diabetes mellitus but without diabetes
}

\author{
Xilin Yang ${ }^{1,2^{*}}$, Huiguang Tian ${ }^{3}$, Fuxia Zhang ${ }^{3}$, Cuiping Zhang ${ }^{3}$, Yi Li $^{3}$, Junhong Leng ${ }^{3}$, Leishen Wang ${ }^{3}$, \\ Gongshu Liư ${ }^{3}$, Ling Dong ${ }^{3}$, Zhijie $\mathrm{Yu}^{4}$, Gang Hu${ }^{5}$ and Juliana CN Chan ${ }^{2}$
}

The online version of the original article can be found under doi:10.1186/s12967-014-0290-2.

\section{Erratum}

After the publication we noticed the misspelling of author Gongshu Liu's name as Gongsu Liu in our article [1]. We apologise for this.

\footnotetext{
Author details

'Department of Epidemiology and Biostatistics, School of Public Health, Tianjin Medical University, Tianjin 300070, China. ${ }^{2}$ Department of Medicine and Therapeutics, Hong Kong Institute of Diabetes and Obesity, The Chinese University of Hong Kong and The Chinese University of Hong Kong-Prince of Wales Hospital-International Diabetes Federation Centre of Education, Hong Kong, China. ${ }^{3} T i a n j i n$ Women and Children's Health Centre, Tianjin, China.

${ }^{4}$ Population Cancer Research Program and Department of Pediatrics, Dalhousie University, Halifax, Canada. ${ }^{5}$ Chronic Disease Epidemiology Laboratory, Pennington Biomedical Research Center, Baton Rouge, Louisiana, USA.
}

Received: 13 November 2014 Accepted: 13 November 2014 Published online: 21 February 2015

\section{Reference}

1. Yang X, Tian H, Zhang F, Zhang C, Li Y, Leng J, et al. A randomised

translational trial of lifestyle intervention using a 3-tier shared care approach on pregnancy outcomes in Chinese women with gestational diabetes mellitus but without diabetes. J Transl Med. 2014;12:290.

\footnotetext{
* Correspondence: yx|@hotmail.com

1 Department of Epidemiology and Biostatistics, School of Public Health, Tianjin Medical University, Tianjin 300070, China

${ }^{2}$ Department of Medicine and Therapeutics, Hong Kong Institute of Diabetes and Obesity, The Chinese University of Hong Kong and The Chinese University of Hong Kong-Prince of Wales Hospital-International Diabetes Federation Centre of Education, Hong Kong, China
}

\section{Submit your next manuscript to BioMed Central and take full advantage of: \\ - Convenient online submission \\ - Thorough peer review \\ - No space constraints or color figure charges \\ - Immediate publication on acceptance \\ - Inclusion in PubMed, CAS, Scopus and Google Scholar \\ - Research which is freely available for redistribution

\section{Biomed Central}

